ARTICLE

\title{
Unveiling how intramolecular stacking modes of covalently linked dimers dictate photoswitching properties
}

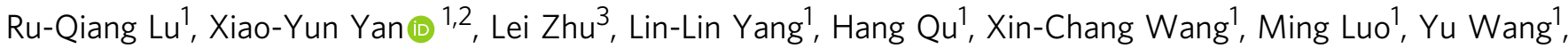 \\ Rui Chen ${ }^{1}$, Xiao-Ye Wang ${ }^{4 \star}$, Yu Lan ${ }^{3 \star}$, Jian Pei ${ }^{5}$, Wengui Weng ${ }^{1}$, Haiping Xia ${ }^{1}{ }^{1} \&$ Xiao-Yu Cao ${ }^{1 \star}$
}

Covalently linked $\pi$-stacked dimers represent the most significant platform for elucidating the relationship between molecular alignments and their properties. Here, we present the onepot synthesis of two intramolecularly $\pi$-stacked dimers and disclose how intramolecular stacking modes dictate photoswitching properties. The dimer, which features cofacially stacked chromophores and geometrically favours intramolecular photochemical [2 +2$]$ cycloadditions, displays a nearly irreversible photoswitching behaviour. By contrast, the dimer, bearing crosswise stacked chromophores, is geometrically unfavourable for the cycloaddition and exhibits a highly reversible photoswitching process, in which the homolysis and reformation of carbon-carbon single bonds are involved. Moreover, the chiral carbon centres of both dimers endow these photoswitches with chirality and the separated enantiomers exhibit tuneable chiroptical properties by photoswitching. This work reveals that intramolecular stacking modes significantly influence the photochemical properties of $\pi$-stacked dimers and offers a design strategy toward chiral photoswitchable materials.

\footnotetext{
${ }^{1}$ State Key Laboratory of Physical Chemistry of Solid Surfaces, Collaborative Innovation Center of Chemistry for Energy Materials (iChEM), Key Laboratory for Chemical Biology of Fujian Province, Department of Chemistry, College of Chemistry and Chemical Engineering, Xiamen University, 361005 Xiamen, China. ${ }^{2}$ Department of Polymer Science, College of Polymer Science and Polymer Engineering, The University of Akron, Akron, OH 44325-3909, USA. ${ }^{3}$ School of Chemistry and Chemical Engineering, Chongqing University, 400030 Chongqing, China. ${ }^{4}$ State Key Laboratory of Elemento-Organic Chemistry, College of Chemistry, Nankai University, 300071 Tianjin, China. ${ }^{5}$ Beijing National Laboratory for Molecular Sciences (BNLMS), the Key Laboratory of Bioorganic Chemistry and Molecular Engineering of Ministry of Education, College of Chemistry and Molecular Engineering, Peking University, 100871 Beijing, China. Dedicated to Professor Jean-Marie Lehn on the occasion of his80th birthday. *email: xiaoye.wang@nankai.edu.cn; lanyu@cqu.edu.cn; xcao@xmu.edu.cn
} 
S ince the first discovery and subsequent synthesis of [2.2] paracyclophane in the middle of the 20 th century ${ }^{1,2}$, covalently linked $\pi$-stacked dimers have attracted intense research interest, ranging from developing new building blocks and synthetic strategies to investigating chemical consequences of their geometries and through-space electronic couplings between $\pi$-conjugated moieties ${ }^{3-6}$. Among these research focuses, the chemical reactivity arising from molecular geometries is of significant interest to generate novel functional properties. For example, benefited from the well-defined alignments of the two $\pi$ moieties, geometrically preferred reactions, such as photoinduced cycloadditions, can be achieved efficiently ${ }^{7-9}$. Another important character of these dimers is their high intramolecular steric repulsion, which may lead to unusually long carbon-carbon single bonds (bond length greater than $1.6 \AA)^{10-12}$. The elongated $\mathrm{C}-\mathrm{C}$ single bonds are accompanied by the decreasing of bond dissociation energies ${ }^{13}$ and thus the increasing of reactivity, for instance, via thermal- or photo-activated bond cleavage ${ }^{14,15}$. These remarkable structural features and their accompanying potential photochemical reactivity make covalently linked dimers promising candidates for photo-responsive materials. Nevertheless, the on-demand control over the relative positions of the neighbouring $\pi$-moieties of such dimers, although highly important for modulating the properties, remains a challenge.

Photoswitchable molecules, which interconvert reversibly between two or more isomers through light irradiation or heat, have received intense attention owing to their wide applications in electronics ${ }^{16-19}$, photopharmacology 20,21 , and molecular machines ${ }^{22,23}$. Transferring the chirality into a photoswitch enables the reversible and precise control over chiral information. Many unconventional applications for photoswitches, such as in manipulating supramolecular chirality 24,25 , liquid crystalline properties $^{26-30}$, and asymmetric catalysis ${ }^{31}$, therefore can be achieved. For instance, Li et al. successfully employed chiral photoswitches as dopants to alter the helical axis of cholesteric liquid crystals ${ }^{27}$. Common photoswitchable building blocks such as azobenzene, diarylethene, and spiropyran, however, do not show chirality or cannot maintain their chirality upon photoswitching. The introduction of stable chirality to them usually requires the additional chiral substituent(s) ${ }^{27,32-35}$ or the chiral environment ${ }^{36}$.

Herein, we report a one-pot synthesis of cyclopentane-bridged dimeric molecules (3a and $\mathbf{3 b}$ ) through cascade nucleophilic additions. The intramolecular stacking modes and thus photoswitching properties can be effectively modulated by changing the substituents on the aromatic skeleton. The well-aligned alkene pairs in endo dimer (3a) easily leads to intramolecular photoinduced $[2+2]$ cycloaddition, which is nearly irreversible upon
UV irradiation at a shorter wavelength. In contrast, the exo dimer (3b) displays outstanding reversible photoswitching properties. The photoisomerization of $\mathbf{3 b}$, undergoing through biradical intermediates, shows excellent fatigue resistance under ambient conditions and large changes in geometries and dipole moments after photoswitching. To our knowledge, incorporating the dimers with different intramolecular stacking modes into photoswitches has never been reported. Furthermore, the chiroptical properties of each enantiomer of $\mathbf{3 b}$ can be dramatically modulated by UV irradiation. The enantiopure $\mathbf{3 b}$ represents a novel kind of photoswitchable building block bearing chiral characteristics, which is a significant complement to the well-established photoswitches. This work, from the fundamental point of view, provides a deep understanding of the relationship between stacking modes in covalently linked dimers and their photoswitching properties. These results would be important in the future design of photoswitches.

\section{Results}

Synthesis of covalently linked dimers. The synthesis of dimers $\mathbf{3 a}$ and $\mathbf{3 b}$ was inspired by a serendipitous finding during the preparation of cyclopentadienone $\mathbf{2 b}$ (Fig. 1), a key synthetic intermediate of corannulene $\mathrm{s}^{37-39}$. Aldol condensation of 4,7dimethylacenaphthenequinone $(\mathbf{1 b})$ and 3 -pentanone produces compound $\mathbf{2 b}$ in the presence of $\mathrm{KOH}$ in methanol after refluxing for $1 \mathrm{~h}^{40}$. An unprecedented dimer $\mathbf{3 b}$ based on cyclopentadienone, however, was obtained in $64 \%$ yield when the reaction time was elongated to $18 \mathrm{~h}$. Different from the previous work in Diels-Alder (D-A) dimerization of cyclopentadienone ${ }^{41}$, fivemembered-ring-bridged dimers are formed in this study due to the presence of $\mathrm{KOH}$, a strong base, in the reaction mixture. To further investigate this reaction, we replaced $\mathbf{l b}(\mathrm{R}=\mathrm{Me})$ with acenaphthenequinone $(\mathbf{1 a}, \mathrm{R}=\mathrm{H})$ as the starting material. Instead of forming an exo dimer like $\mathbf{3 b}$, an endo-dimer $\mathbf{3} \mathbf{a}$ was obtained in $38 \%$ yield. The photoisomerization of $\mathbf{3} \mathbf{a}$ and $\mathbf{3 b}$ is also displayed in Fig. 1, which will be discussed in details later. All new compounds were characterized by nuclear magnetic resonance (NMR) and high-resolution mass spectrometry (HRMS).

Single-crystal analysis of the dimers. The structures and configurations of $\mathbf{3 a}$ and $\mathbf{3 b}$ are unambiguously confirmed by singlecrystal X-ray analysis (Fig. 2 and Supplementary Table 1). The single-crystal structures of $\mathbf{4 a}$ and $\mathbf{4 b}$ are also shown here, which will be discussed later. A pair of enantiomers are observed for both $\mathbf{3 a}$ and $\mathbf{3 b}$ in single crystals (Supplementary Fig. 1). In dimers $\mathbf{3} \mathbf{a}$ and $\mathbf{3} \mathbf{b}$, two conjugated monomers are bridged by a five-membered ring. In dimer $\mathbf{3 a}$, the monomers are aligned on

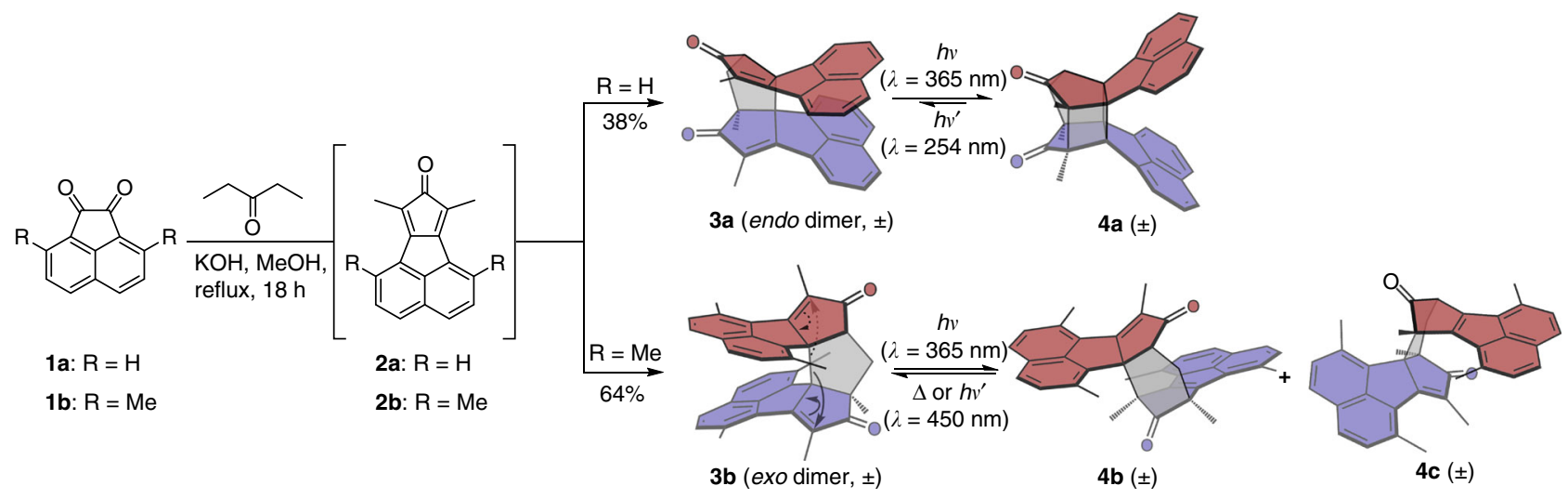

Fig. 1 One-pot synthesis and photochemical reactions of $\mathbf{3} \mathbf{a}$ and $\mathbf{3} \mathbf{b}$. Both $\mathbf{3} \mathbf{a}$ and $\mathbf{3} \mathbf{b}$ are obtained as a pair of enantiomers. The photochemical rearrangements of $\mathbf{3} \mathbf{b}$ leading to $\mathbf{4 b}$ and $\mathbf{4 c}$ are indicated by solid and dashed arrows, respectively. 
a

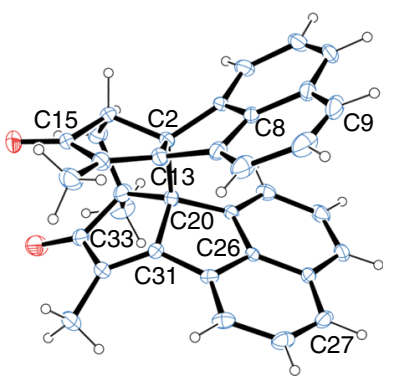

b

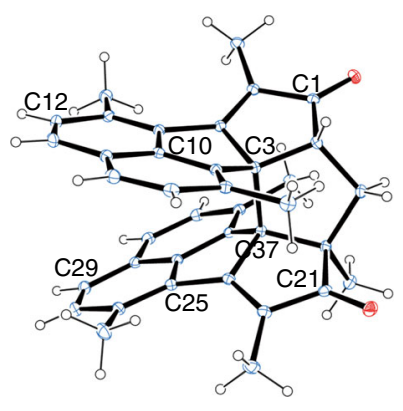

C

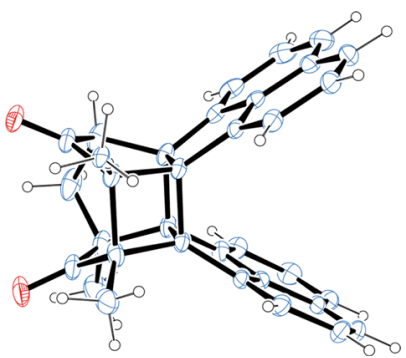

d

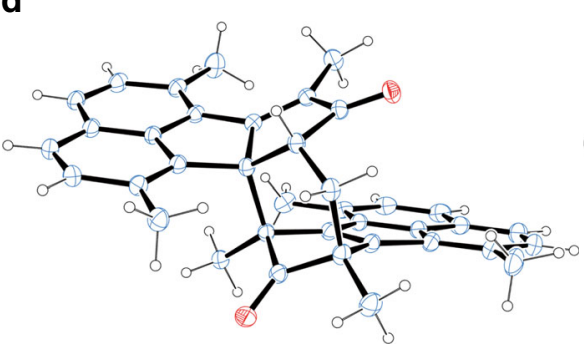

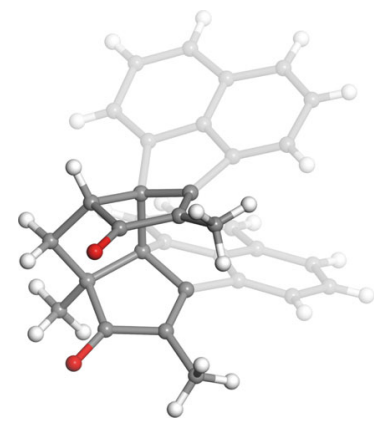
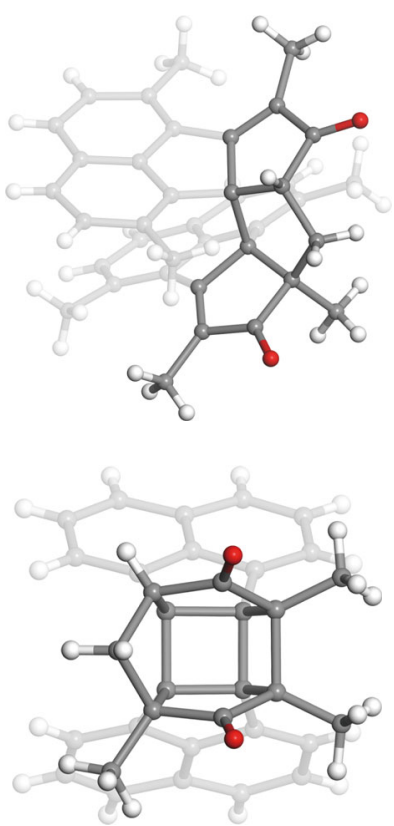

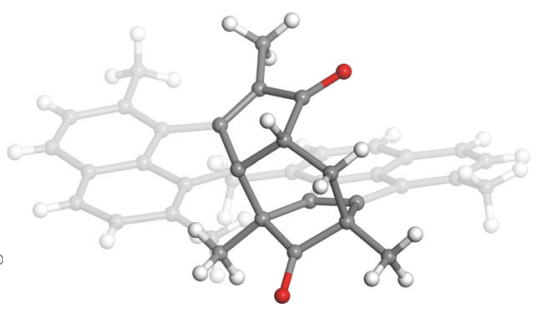

Fig. 2 Single-crystal structures. a 3a, b 3b, c 4a, and $\mathbf{d} \mathbf{4 b}$. Thermal displacement ellipsoids are shown at the $25 \%$ probability level. The annulated rings are highlighted.

the same side of the bridge, hence giving an endo configuration. From the top view of $\mathbf{3 a}$, two chromophores containing alkene moieties are nearly cofacially aligned. The stacking angle $(\theta)$, as defined in Supplementary Table 2, was determined as $11.4^{\circ}$. The distances between two intramolecular stacked arms are ranging from 2.67 to $5.29 \AA$ (Supplementary Table 2). Arising from the steric hindrance between two chromophores, the length of the bond connecting two chromophores (C2-C20 single bond) is $1.66 \AA$, much larger than the typical length for a carbon-carbon single bond $(1.54 \AA)^{42}$. Dimer $3 \mathbf{b}$ exhibits an exo configuration with the two chromophores stacked crosswise. The stacking angle $(\theta)$ is determined as $102.8^{\circ}$, much larger than that of $\mathbf{3 a}$ (Fig. $2 \mathrm{~b}$ ). The distances between face-to-face benzenes are ranging from 3.31 to $4.45 \AA$ (Supplementary Table 2). The C3-C37 single bond exhibits a length of $1.62 \AA$, which is also larger than the typical length of carbon-carbon single bond.
Mechanism of dimerization. To give insights into the reaction mechanism of the dimerization process, a cascade process of nucleophilic additions is proposed (Fig. 3). The mechanism for the formation of $\mathbf{3 a}$ is illustrated in Fig. 3a ( $\mathbf{3} \mathbf{b}$ was formed in a similar process but with a different stereoselectivity). The proposed mechanism can be roughly divided into three stages. The first stage is an Aldol condensation between 1a and 3-pentanone, producing the dehydrated product $2 \mathbf{a}$. This reaction has been thoroughly investigated, and 2 a can be separated out ${ }^{40}$. The second stage is a nucleophilic addition between two cyclopentadienonyl derivatives (2a) after one of them is deprotonated on the $\beta$-carbon of its carbonyl group. In this step, two out of four chiral centres are determined, and the linkage between monomers is formed, producing enolates 7 . In the third step, a Michael addition takes place, thus presenting the final configuration. 
a

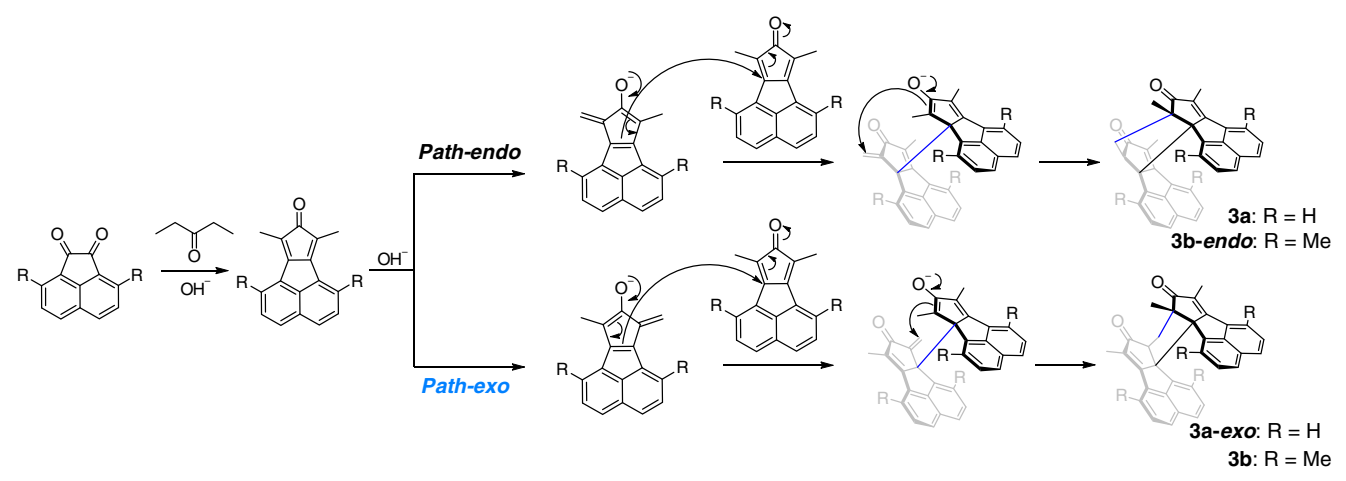

b

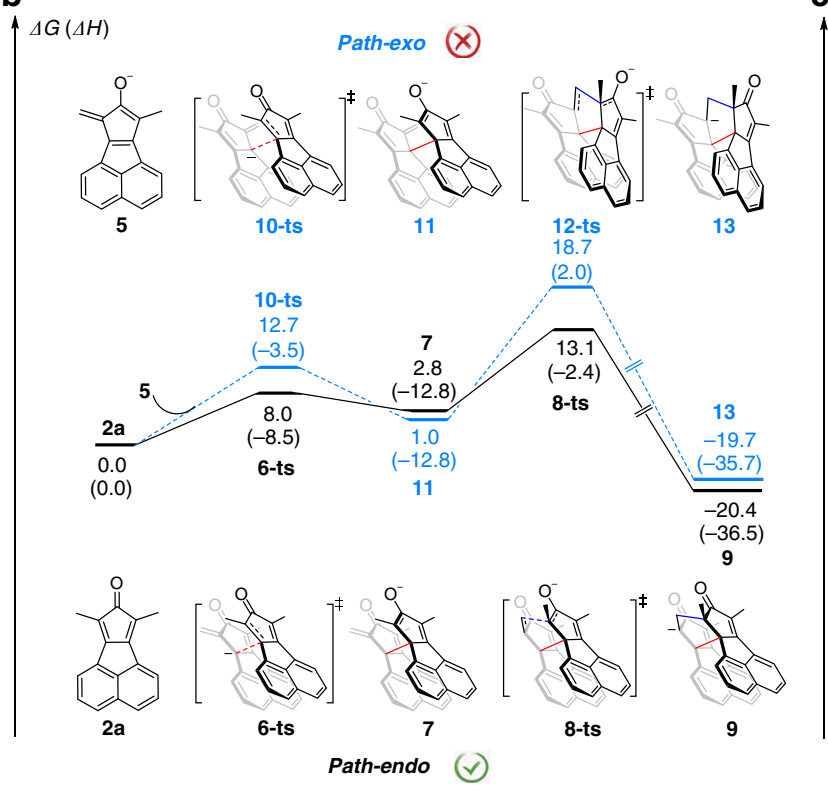

C

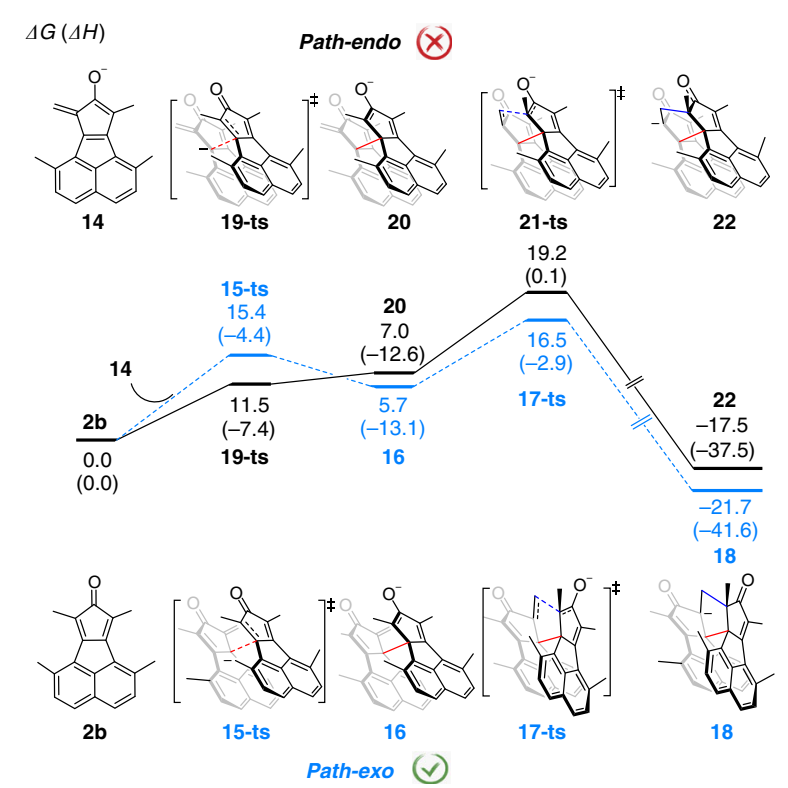

Fig. 3 Proposed mechanism. a Proposed mechanism of the nucleophilic addition cascade process. Free energy profiles of Path-endo (black) and Path-exo (blue) for the dimerization of $\mathbf{b}$ reactant $\mathbf{2} \mathbf{a}$ and $\mathbf{c}$ reactant $\mathbf{2} \mathbf{b}$. Values (in $\mathrm{kcal} \cdot \mathrm{mol}^{-1}$ ) represent the relative free energies calculated by the $\omega \mathrm{B} 97 \mathrm{X}-\mathrm{D} / / \mathrm{M} 11$ method in methanol. The values in parentheses are the relative enthalpy.

To elucidate the origin of stereoselectivities during the formation of $\mathbf{3} \mathbf{a}$ and $\mathbf{3} \mathbf{b}$, density functional theory (DFT) calculations were employed. Taking 3a for example, two competitive pathways leading to 3a or 3a-exo are considered and the free energy profiles are summarized in Fig. $3 \mathrm{~b}$ and Supplementary Table 3. The total free energy of cyclopentadienonyl $\mathbf{2 a}$ and its conjugate base $\mathbf{5}$ (which could be generated by deprotonation of $\mathbf{2 a}$ in the presence of base) is set as the relative zero in the free energy profiles. In the Path-endo, the initial intermolecular nucleophilic addition of $\mathbf{5}$ to the benzyl position on 2a via transition state 6-ts generates enolate complex 7 with a free energy barrier of $8.0 \mathrm{kcal} \cdot \mathrm{mol}^{-1}$. The subsequent intramolecular cyclization leads to the formation of intermediate 9, from which the endo dimeric product 3a can be generated after protonation. The overall activation free energy of Path-endo was calculated as $13.1 \mathrm{kcal} \cdot \mathrm{mol}^{-1}$. Alternatively, the isomer 3a-exo can also be generated in a similar way (Path-exo). The corresponding activation free energy of this process (via 12-ts) was calculated to be $18.7 \mathrm{kcal} \cdot \mathrm{mol}^{-1}$, much higher than that of Path-endo (via 8-ts), indicating that the generation of $\mathbf{3 a}$ in the endo configuration is more favourable. Non-covalent interaction (NCI) analysis ${ }^{43}$ reveals that the energetic discrepancy is mainly contributed by intramolecular $\pi-\pi$ interactions between two fragments lowering the energy of transition state 8-ts (Supplementary Fig. 2). However, when methyl groups are introduced on naphthalene in the case of $\mathbf{3 b}$, the steric hindrance of methyl groups results in a high activation free energy of $19.2 \mathrm{kcal} \cdot \mathrm{mol}^{-1}$ in Path-endo, which is higher than that in Path-exo $\left(16.5 \mathrm{kcal} \cdot \mathrm{mol}^{-1}\right.$, Fig. $3 \mathrm{c}$ ), leading to the preferable formation of $\mathbf{3 b}$ in the exo configuration. These theoretical calculations confirm that both $\pi-\pi$ interactions and steric hindrance play important roles in the stereoselectivity of this reaction and illustrate that how the small changes of substituents ( $\mathrm{H}$ vs. $\mathrm{Me}$ ) afford completely different configurations.

Photoswitching properties of the dimers. Initial insights into the photochemical behaviours of cyclopentadione dimers produced by $\mathrm{D}-\mathrm{A}$ reactions in $1980 \mathrm{~s}^{41,44,45}$ inspired us to investigate the photoswitching properties of the two obtained dimers. The photoisomerization results of $\mathbf{3} \mathbf{a}$ and $\mathbf{3} \mathbf{b}$ is shown in Fig. 1. The parallel alkene pairs in 3a geometrically favour the photochemical $[2+2]$ cycloaddition to produce $4 a$. The intramolecular cycloaddition reaction of $3 \mathbf{a}$ in $\mathrm{CHCl}_{3}$ was monitored by in-situ UV-vis absorption spectroscopy, which indicates that the reaction finishes in less than $16 \mathrm{~s}$ upon UV irradiation at $365 \mathrm{~nm}$ (Supplementary Fig. 3). The quantitative conversion from $3 a$ to $4 a$ was demonstrated by in-situ ${ }^{1} \mathrm{H}$ NMR spectroscopy (Supplementary Fig. 4). The cycloaddition reaction can even happen in single 
crystals, which was confirmed by in-situ single-crystal X-ray diffraction of $\mathbf{3 a}$ before and after UV irradiation. The cycloaddition is irreversible upon heating at $50{ }^{\circ} \mathrm{C}$ and nearly irreversible upon UV irradiation at a shorter wavelength $(\lambda=254 \mathrm{~nm})$. Upon UV irradiation at $254 \mathrm{~nm}$ for $9.5 \mathrm{~h}$, less than $4 \%$ of $\mathbf{4 a}$ undergoes photocleavage of the cyclobutane to recover to 3a (Supplementary Fig. 4). Nonetheless, the four chiral centres on 3a endow its enantiopure forms, i.e. RSSS-3a and SRRR-3a (Supplementary Fig. 1), with tuneable chiroptical properties upon UV irradiation (Supplementary Fig. 12a and Fig. 12b).

Dimer 3b, however, exhibits completely different photoisomerization behaviours. Two new sets of signals appeared in ${ }^{1} \mathrm{H}$ NMR upon UV irradiation at $365 \mathrm{~nm}$ (Fig. 4b). This photoisomerization is reversible upon heating. After being heated at $40^{\circ} \mathrm{C}$ for $8 \mathrm{~h}$, the mixture completely changed to the initial state (Fig. 4c). The photoisomerization products of $\mathbf{3 b}$ can be separated out from the starting material by column chromatography over silica gel. A yellow solid containing two compounds (i.e. $\mathbf{4 b}$ and $4 \mathrm{c}$, which cannot be separated due to their similar polarities and thus are characterized as a mixture) was obtained. The $[\mathbf{4 b}]:[\mathbf{4 c}]$ ratio is around 4.1: 1 (determined from the integrations of the peaks at 7.77-7.78 ppm for $\mathbf{4 b}$ and at 7.79-7.80 $\mathrm{ppm}$ for $4 \mathrm{c}$ in ${ }^{1} \mathrm{H}$ NMR spectra). The structure of the main portion $\mathbf{4 b}$ was determined by single-crystal X-ray analysis (Fig. 2d). One of the arms of $\mathbf{4 b}$ isomerizes to an acenaphthylene derivative and its relative orientation to the other arm is also changed. $\sigma[1,3]$ shifts were first considered as the possible mechanism of the isomerization, but it should be noted that the thermal $[1,3]$ shifts proceeding through suprafacial shifts are forbidden ${ }^{46}$. We therefore proposed a biradical mechanism to explain this isomerization (Fig. 5). Upon

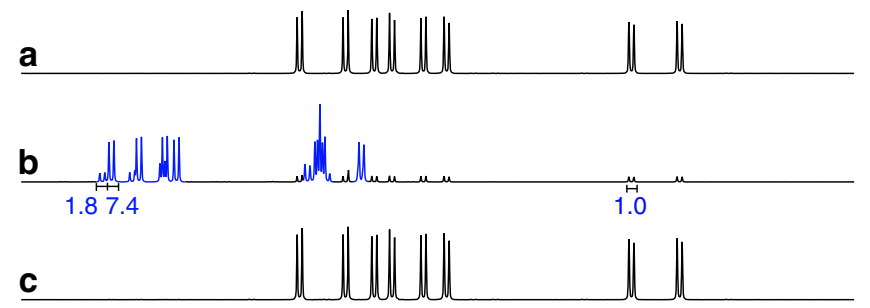

$\begin{array}{lllllllllllllllll}7.9 & 7.8 & 7.7 & 7.6 & 7.5 & 7.4 & 7.3 & 7.2 & 7.1 & 7.0 & 6.9 & 6.8 & 6.7 & 6.6 & 6.5 & 6.4\end{array}$ $\delta(\mathrm{ppm})$

Fig. 4 Photo- and thermal-isomerization monitored by NMR. ${ }^{1} \mathrm{H}$ NMR spectra of $\mathbf{3 b} \mathbf{a}$ in the pristine state, $\mathbf{b}$ in the photostationary state $([\mathbf{4 b}+\mathbf{4} \mathbf{c}] /[\mathbf{3 b}]=90 / 10$ from the integrations of the peaks at 7.77 $-7.80 \mathrm{ppm}$ and $6.78-6.79 \mathrm{ppm})$ and $\mathbf{c}$ in the recovered state after being heated at $40^{\circ} \mathrm{C}$ for $8 \mathrm{~h}$ in $\mathrm{CD}_{2} \mathrm{Cl}_{2}(4.6 \mathrm{mM})$.
UV irradiation, the overlong $\mathrm{C} 3-\mathrm{C} 37$ single bond (Fig. 2), resulting from the steric repulsion between two cyclopentadienone derivatives, is broken to form biradical intermediate $\mathbf{A}$, which has two resonant structures $\mathbf{B}$ and $\mathbf{C}$. The biradicals of $\mathbf{B}$ and $\mathbf{C}$ form new carbon-carbon single bonds to produce $\mathbf{4 b}$ and $\mathbf{4 c}$, respectively. The ${ }^{1} \mathrm{H}$ NMR spectrum of the less portion is in accordance with the structure of $\mathbf{4 c}$ (Supplementary Fig. 5), which confirms the proposed mechanism. This homolytic bond breaking and formation mechanism is also found in imidazole-based photoswitches ${ }^{47,48}$. DFT calculations reveal that the energy of $\mathbf{4 b}$ is about $1 \mathrm{kcal} \cdot \mathrm{mol}^{-1}(\omega \mathrm{B} 97 \mathrm{X}-\mathrm{D} / 6-31 \mathrm{G}(\mathrm{d}, \mathrm{p})$ in the gas phase) lower than that of $\mathbf{4 c}$, which accounts for the larger population of 4b than that of $\mathbf{4 c}$ in the photostationary state (PSS). The conversion percentage from $\mathbf{3 b}$ to $\mathbf{4 b}$ and $\mathbf{4} \mathbf{c}$ in the PSS determined by high-performance liquid chromatography (HPLC) is $93 \%$ (Supplementary Fig. 6), in agreement with the ${ }^{1} \mathrm{H}$ NMR result $(90 \%)$. The similar isomerization via biradical intermediates was not observed for $3 \mathbf{a}$, although the length of $\mathrm{C} 2-\mathrm{C} 20$ bond for $3 a$ is $1.66 \AA$, probably because the rate of photo-induced cycloaddition is much faster than that of the isomerization through biradical intermediates.

This photoisomerization results in large difference in geometries and dipole moments between $\mathbf{3 b}$ and its photoisomers. Compounds $\mathbf{4 b}$ and $\mathbf{4 c}$ show similar dipole moments, geometries, and absorption (Supplementary Table 4 and Supplementary Fig. 7). Therefore, even though they cannot be easily separated, they can still be regarded as one portion when they are used as a photoswitch. Herein, the main portion $\mathbf{4 b}$ is used as an example to illustrate the difference from $\mathbf{3 b}$. The end-to-end distances are increased from $4.7 \AA$ for $\mathbf{3 b}$ to $8.8 \AA$ for $\mathbf{4 b}$ (Supplementary Table 4), generating a difference of $4.1 \AA$ in length, which is larger than that of the $E / Z$ isomerization of azobenzene $\left(\sim 3.5 \AA^{17}\right)$. This large geometrical change in chemical structures is expected to induce significant morphological difference in hierarchical assemblies and thus provides the possibilities in the control of protein folding and unfolding ${ }^{49}$, artificial molecular muscles ${ }^{50}$ and supramolecular chemistry ${ }^{51}$. In addition, the dipole moments change from 6.2 Debye for $\mathbf{3 b}$ to 2.7 Debye for $\mathbf{4 b}$ due to the shift of relative orientations of two arms. To reveal kinetic processes of the thermal isomerization from $\mathbf{4 b}$ and $\mathbf{4 c}$ to $\mathbf{3 b}$, time-dependent ${ }^{1} \mathrm{H}$ NMR spectra of the solution of $\mathbf{3 b}$ in the PSS at various temperatures were measured. The thermal isomerizations of $\mathbf{4 b}$ and $\mathbf{4 c}$ follow first-order kinetics (Supplementary Fig. 8 and Supplementary Table 5). At room temperature $(298 \mathrm{~K})$, the activation energy of the thermal isomerization from $\mathbf{4 b}$ to $\mathbf{3 b}$ was determined to be $24.8 \mathrm{kcal} \cdot \mathrm{mol}^{-1}$ with a half-life of $3.87 \mathrm{~h}$ and that from $\mathbf{4 c}$ to $\mathbf{3 b}$ was $24.5 \mathrm{kcal} \cdot \mathrm{mol}^{-1}$ with a half-life of $4.05 \mathrm{~h}$.

The photoswitching process of $\mathbf{3 b}$ was also monitored by UVvis spectroscopy (Fig. 6a-c). Three isobestic points at $300 \mathrm{~nm}, 371$

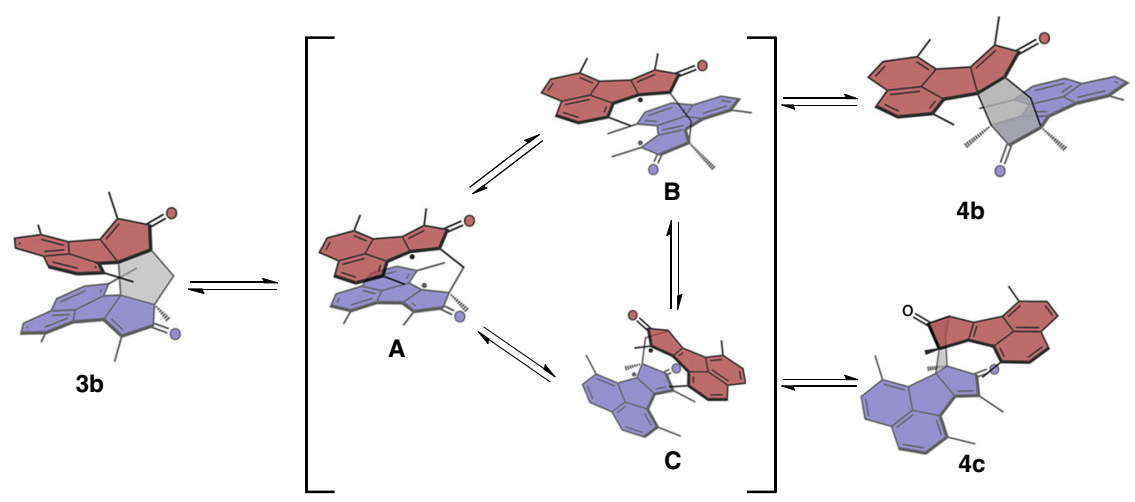

Fig. $\mathbf{5}$ Proposed biradical mechanism of the photoswitching process of $\mathbf{3 b}$. The photoisomerization from $\mathbf{3 b}$ to $\mathbf{4 b}$ was shown in Supplementary Movie 1 . 

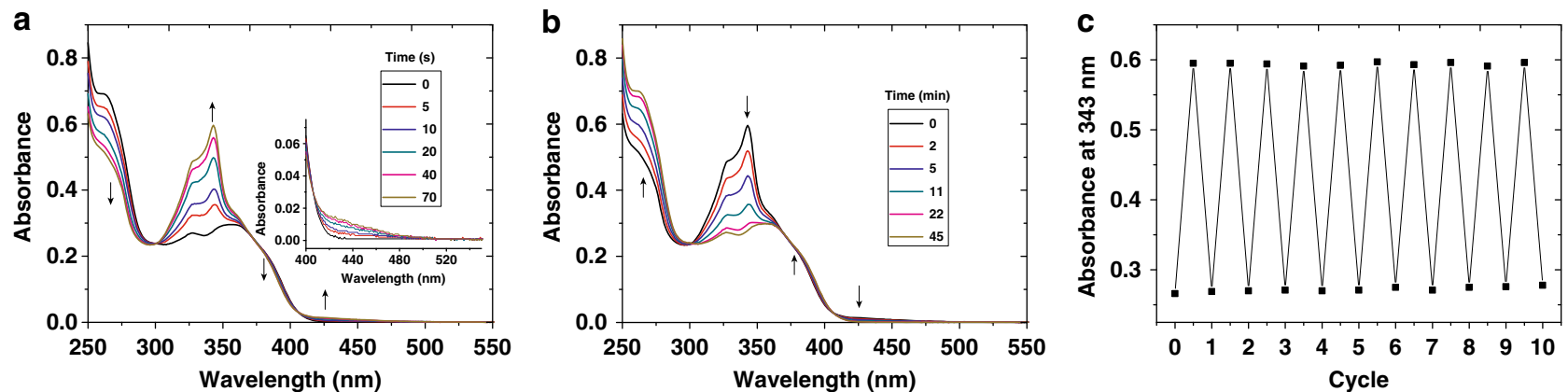

Fig. 6 Photo- and thermal-isomerization monitored by absorption spectra. Absorption of $\mathbf{3 b}$ a upon UV irradiation $365 \mathrm{~nm}$ and $\mathbf{b}$ then heated at $55^{\circ} \mathrm{C}$ $\left(\mathrm{CHCl}_{3}, 2.24 \times 10^{-5} \mathrm{M}\right)$; c absorbance at $343 \mathrm{~nm}$ upon UV irradiation at $365 \mathrm{~nm}$ for $70 \mathrm{~s}$ and then heated at $55^{\circ} \mathrm{C}$ for $45 \mathrm{~min}$ in repeated cycles.
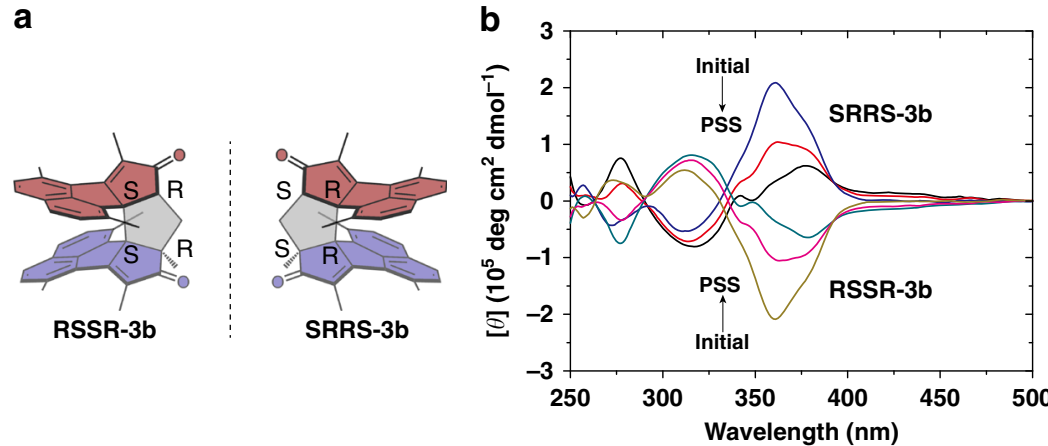

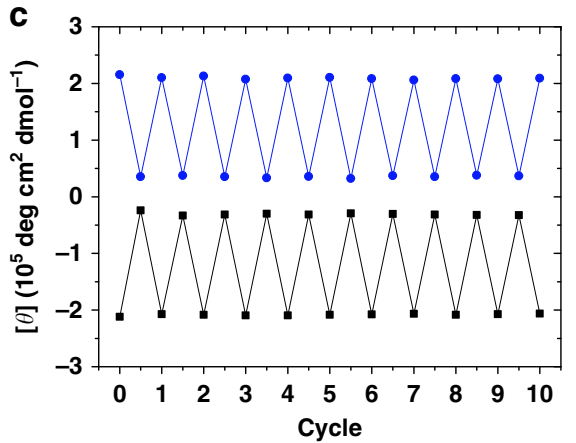

Fig. $\mathbf{7}$ Chiral photoswitching of $\mathbf{3 b}$. a Enantiomers of $\mathbf{3 b}$. $\mathbf{b}$ CD spectra of RSSR-3b and SRRS-3b upon UV irradiation at $365 \mathrm{~nm}$. c Molar ellipticity at $360 \mathrm{~nm}$ upon UV irradiation at $365 \mathrm{~nm}$ for $70 \mathrm{~s}$ and then heated at $55^{\circ} \mathrm{C}$ for $45 \mathrm{~min}$ in repeated cycles (SRRS-3b in blue line and RSSR-3b in black line).

$\mathrm{nm}$ and $406 \mathrm{~nm}$ are observed upon UV irradiation at $365 \mathrm{~nm}$. The absorbance from $300 \mathrm{~nm}$ to $369 \mathrm{~nm}$ and from $406 \mathrm{~nm}$ to $500 \mathrm{~nm}$ increases as the UV irradiation time extends. The onset absorbance red-shifts from 428 to $500 \mathrm{~nm}$. The photoisomerizations reach the PSS in less than $70 \mathrm{~s}$. After being heated at $55^{\circ} \mathrm{C}$ for less than $45 \mathrm{~min}$, the mixture recovers to pristine state entirely. To test the photostability of $\mathbf{3 b}, \mathbf{4 b}$, and $\mathbf{4 c}$, the solution of $\mathbf{3 b}$ was alternately irradiated with UV light and heated, and the absorbance at $343 \mathrm{~nm}$ was selected to monitor the photoswitching process. The switch exhibits no fatigue after 10 repeated cycles under ambient conditions (Fig. $6 \mathrm{c}$, temperature: $\sim 28^{\circ} \mathrm{C}$, humidity: 75-90\%), indicating a large fatigue resistance of the photoswitching process. To confirm if the thermal-back isomerization can be achieved by light irradiation, the PSS solution of $\mathbf{3 b}$ was irradiated with visible light at $450 \mathrm{~nm}$. The back isomerization from $\mathbf{4 b}$ and $\mathbf{4} \mathbf{c}$ to $\mathbf{3 b}$ is indeed accelerated (Supplementary Fig. 9), revealing the photoisomerization of $\mathbf{3 b}$ is reversible both upon heating and light irradiation.

The enantiomers of $\mathbf{3 b}$ (RSSR-3b and SRRS-3b) can be separated by chiral HPLC (Supplementary Fig. 10b). Comparison of their circular dichroism (CD) spectra and the corresponding DFT-simulated ones reveals that the component eluting at 13.6 min is RSSR-3b, and that eluting at $15.7 \mathrm{~min}$ is RSSR-3b (Supplementary Fig. 11b). As expected, RSSR-3b and SRRS-3b show mirror-like CD spectra (Fig. 7b). The chiroptical properties of RSSR-3b and SRRS-3b can be altered by UV irradiation at 365 $\mathrm{nm}$. For example, the exciton couplet of SRRS-3b at $360 \mathrm{~nm}$ weakens as the irradiation time increases and fully recovers after being heated at $55^{\circ} \mathrm{C}$ for $45 \mathrm{~min}$ (Supplementary Figs. 12c and $12 \mathrm{~d})$. The molar ellipticity of SRRS-3b at $360 \mathrm{~nm}$ is switched from $2.1 \times 10^{5}$ (ON state) to $3.7 \times 10^{4} \mathrm{deg} \cdot \mathrm{cm}^{2} \cdot \mathrm{dmol}^{-1}$ (OFF state) with a ON/OFF ratio at 5.7 upon UV irradiation. The chiral properties exhibit no decay after ten repeated switching cycles (Fig. 7c). Such high fatigue resistance under ambient conditions outperforms that of most reported chiral photoswitches $32,35,47$. These outstanding properties make the chiral photoswitches highly promising building blocks for the applications in modulating supramolecular chirality, chiral information storage, asymmetric synthesis, etc.

\section{Discussion}

In summary, a new type of cyclopentane-bridged dimeric molecules with different intramolecular stacking modes have been synthesized in a concise one-pot procedure. Their intramolecular stacking modes (i.e. endo or exo configurations) can be modulated by modifying the substituents on the aromatic core, as confirmed by single-crystal structures. Theoretical calculations reveal that such stereoselectivity resulted from the competition between steric repulsion and $\pi-\pi$ interactions. The endo-dimer (3a) displays a nearly irreversible photoswitching process through intramolecular photochemical $[2+2]$ cycloaddition and its reverse reaction. The exo-dimer (3b) undergoes reversible photoswitching processes via biradical intermediates. This work demonstrates the possibility of tuning intramolecular stacking modes of rigidly linked $\pi$-stacked molecules by altering the substituents and provides a chiral photoswitchable building block, i.e. exo-dimer, with excellent properties such as high fatigue resistance and large changes in geometries, chiroptical properties, and dipole moments during photoisomerizations. The exo-dimer is a significant complement to the well-established photoswitches as exemplified by azobenzene, diarylethene, and spiropyran. Further fine-tuning of the photoswitching properties and exploration of their potential applications, for example, in single-molecule electronics $^{52,53}$, singlet fissions ${ }^{54,55}$, bioimaging ${ }^{56}$, and supramolecular chemistry $49,51,57,58$, require the facile chemical modifications of the exo-dimer. The introduction of reactive groups such as halogens within the precursors may provide photoswitching 
dimers allowing for versatile late-stage functionalization, which is in progress in our group.

\section{Methods}

Synthesis of 3a. A solution of $\mathrm{KOH}(862 \mathrm{mg}, 15.4 \mathrm{mmol})$ in methanol $(10 \mathrm{~mL})$ was added dropwise to a mixture of 1 a $(350 \mathrm{mg}, 1.92 \mathrm{mmol}), 3$-pentanone $(661 \mathrm{mg}$, $7.68 \mathrm{mmol})$ and methanol $(10 \mathrm{~mL})$ at room temperature. The mixture was stirred at reflux for $18 \mathrm{~h}$. The precipitation was filtered, washed with water and dried under vacuum. The crude product was further purified by column chromatography over neutral alumina (eluent: chloroform/hexane $=3 / 7)$ to give $3 \mathbf{a}(168 \mathrm{mg}, 38 \%)$ as a pale-yellow solid.

Synthesis of $\mathbf{3 b}$. Compound $\mathbf{3 b}$ was synthesized using the same methods as described for 3a. It was obtained as a pale-yellow solid ( $277 \mathrm{mg}, 64 \%)$.

The detailed procedures and characterization are presented in Supplementary Methods. All NMR spectra are shown in Supplementary Figs. 13-29.

Single-crystal X-ray diffraction. Single-crystal diffraction data were collected on a XtaLAB Synergy, Dualflex, HyPix single-crystal diffractometer using $\mathrm{Cu} \mathrm{Ka}(\lambda=$ $1.54184 \AA$ ) micro-focus sealed X-ray tube at $100 \mathrm{~K}$ for $\mathbf{3 a}, \mathbf{3 b}$ and $\mathbf{4 a}$ and on a Rigaku SuperNova X-Ray single-crystal diffractometer using Cu Ka $(\lambda=1.54184$ A) micro-focus X-ray sources at $150 \mathrm{~K}$ for $\mathbf{4 b}$.

Computational methods. DFT calculations on mechanisms were carried out at the $\omega \mathrm{B} 97 \mathrm{X}-\mathrm{D} / 6-311+\mathrm{G}(\mathrm{d}, \mathrm{p}) / / \mathrm{M} 11 / 6-31 \mathrm{G}(\mathrm{d})$ levels of theory in methanol using a SMD solvation model. DFT calculations on geometries and TD-DFT calculations on optical spectra were performed at the $\omega \mathrm{B} 97 \mathrm{X}-\mathrm{D} / 6-31 \mathrm{G}(\mathrm{d}, \mathrm{p})$ level of theory in the gas phase. The coordinates of all optimized structures are provided in Supplementary Data 1. Detailed methods are presented in the Supplementary Methods.

Kinetic measurements. The solution of $\mathbf{3 b}$ in $\mathrm{CDCl}_{3}(3.85 \mathrm{mM})$ was irradiated with UV light $(\lambda=365 \mathrm{~nm})$ to the photostationary state and used immediately. The solution of the mixture of $\mathbf{3 b} \mathbf{b} \mathbf{4 b}$, and $\mathbf{4} \mathbf{c}$ was kept at various temperature $(303,308$, 313,318 , and $323 \mathrm{~K}$ ) in dark and characterized by time-dependent ${ }^{1} \mathrm{H}$ NMR spectra. The temperature was controlled by a water bath. The ambient temperature was around $25^{\circ} \mathrm{C}$. The samples were dipped in ice water for $15 \mathrm{~s}$ before the acquisition of ${ }^{1} \mathrm{H}$ NMR spectra to reduce the decay of the photoisomers resulting from the lingering warmth during the measurements. The concentrations of $\mathbf{3 b}, \mathbf{4} \mathbf{b}$, and $4 \mathrm{c}$ in the mixture were determined by the integrations of the peaks with the chemical shifts at $1.19 \mathrm{ppm}$ for $\mathbf{3 b}, 0.87 \mathrm{ppm}$ for $\mathbf{4 b}$, and $0.77-0.78 \mathrm{ppm}$ for $\mathbf{4 c}$. The initial concentrations were around $2.85 \mathrm{mM}$ for $\mathbf{4 b}$ and around $0.61 \mathrm{mM}$ for $\mathbf{4 c}$.

\section{Data availability}

All data used for this paper are available from the authors on request. The X-ray crystallographic coordinates for structures reported in this study have been deposited at The Cambridge Crystallographic Data Centre (CCDC) under deposition numbers 1913518 for 3a, 1939142 for $\mathbf{3 b}, 1832043$ for $\mathbf{4 a}$, and 1832044 for $\mathbf{4 b}$. These data can be obtained free of charge from The Cambridge Crystallographic Data Centre at www.ccdc. cam.ac.uk/data_request/cif.

Received: 2 May 2019; Accepted: 7 November 2019;

Published online: 02 December 2019

\section{References}

1. Brown, C. J. \& Farthing, A. C. Preparation and structure of di- $p$-xylylene. Nature 164, 915 (1949).

2. Cram, D. J. \& Steinberg, H. Macro Rings. I. Preparation and spectra of the paracyclophanes. J. Am. Chem. Soc. 73, 5691-5704 (1951).

3. Ghasemabadi, P. G., Yao, T. \& Bodwell, G. J. Cyclophanes containing large polycyclic aromatic hydrocarbons. Chem. Soc. Rev. 44, 6494-6518 (2015).

4. Liu, Z., Nalluri, S. K. M. \& Stoddart, J. F. Surveying macrocyclic chemistry: from flexible crown ethers to rigid cyclophanes. Chem. Soc. Rev. 46, 2459-2478 (2017).

5. Canevet, D., Pérez, E. M. \& Martín, N. Wraparound hosts for fullerenes: tailored macrocycles and cages. Angew. Chem. Int. Ed. 50, $9248-9259$ (2011).

6. Boydston, A. J. et al. [2.2]Paracyclophane/dehydrobenzoannulene hybrids transannular delocalization in open-circuited conjugated macrocycles. Angew. Chem., Int. Ed. 40, 2986-2989 (2001).

7. Yoshizawa, M., Tamura, M. \& Fujita, M. Diels-Alder in aqueous molecular hosts: unusual regioselectivity and efficient catalysis. Science 312, 251-254 (2006).
8. Hayashi, T. et al. Excimer fluorescence and photodimerization of anthracenophanes and 1,2-dianthrylethanes. J. Am. Chem. Soc. 98, 5910-5913 (1976).

9. Brogaard, R. Y. et al. Pseudo-bimolecular [2+2] cycloaddition studied by time-resolved photoelectron spectroscopy. Chem. Eur. J. 17, 3922-3931 (2011).

10. Suzuki, T., Takeda, T., Kawai, H. \& Fujiwara, K. Ultralong C-C bonds in hexaphenylethane derivatives. Pure Appl. Chem. 80, 547 (2008).

11. Dodziuk, H. Strained Hydrocarbons (Wiley-VCH, 2009).

12. Ishigaki, Y., Shimajiri, T., Takeda, T., Katoono, R. \& Suzuki, T. Longest C-C single bond among neutral hydrocarbons with a bond length beyond $1.8 \AA$. Chem 4, 795-806 (2018).

13. Zavitsas, A. A. The relation between bond lengths and dissociation energies of carbon-carbon bonds. J. Phys. Chem. A 107, 897-898 (2003)

14. Rüchardt, C. \& Beckhaus, H. D. Towards an understanding of the carboncarbon bond. Angew. Chem. Int. Ed. 19, 429-440 (1980).

15. Koch, T. H., Olesen, J. A. \& DeNiro, J. Unusually weak carbon-carbon single bond. J. Am. Chem. Soc. 97, 7285-7288 (1975).

16. Jia, C. et al. Covalently bonded single-molecule junctions with stable and reversible photoswitched conductivity. Science 352, 1443-1445 (2016).

17. Russew, M.-M. \& Hecht, S. Photoswitches: from molecules to materials. $A d v$ Mater. 22, 3348-3360 (2010).

18. Zhang, J., Zou, Q. \& Tian, H. Photochromic materials: more than meets the eye. Adv. Mater. 25, 378-399 (2013).

19. Wang, L. \& Li, Q. Photochromism into nanosystems: towards lighting up the future nanoworld. Chem. Soc. Rev. 47, 1044-1097 (2018).

20. Velema, W. A., Szymanski, W. \& Feringa, B. L. Photopharmacology: beyond proof of principle. J. Am. Chem. Soc. 136, 2178-2191 (2014).

21. Broichhagen, J., Frank, J. A. \& Trauner, D. A roadmap to success in photopharmacology. Acc. Chem. Res. 48, 1947-1960 (2015).

22. Erbas-Cakmak, S., Leigh, D. A., McTernan, C. T. \& Nussbaumer, A. L. Artificial molecular machines. Chem. Rev. 115, 10081-10206 (2015).

23. Kay, E. R., Leigh, D. A. \& Zerbetto, F. Synthetic molecular motors and mechanical machines. Angew. Chem., Int. Ed. 46, 72-191 (2007).

24. Hayasaka, H., Miyashita, T., Tamura, K. \& Akagi, K. Helically $\pi$-stacked conjugated polymers bearing photoresponsive and chiral moieties in side chains: reversible photoisomerization-enforced switching between emission and quenching of circularly polarized fluorescence. Adv. Funct. Mater. 20, 1243-1250 (2010).

25. Zhao, D., van Leeuwen, T., Cheng, J. \& Feringa, B. L. Dynamic control of chirality and self-assembly of double-stranded helicates with light. Nat. Chem. 9, 250 (2016)

26. Qin, L., Gu, W., Wei, J. \& Yu, Y. Piecewise phototuning of self-organized helical superstructures. Adv. Mater. 30, 1704941 (2018).

27. Zheng, Z.-g et al. Three-dimensional control of the helical axis of a chiral nematic liquid crystal by light. Nature 531, 352-356 (2016).

28. Pijper, D., Jongejan, M. G. M., Meetsma, A. \& Feringa, B. L. Light-controlled supramolecular helicity of a liquid crystalline phase using a helical polymer functionalized with a single chiroptical molecular switch. J. Am. Chem. Soc. 130, 4541-4552 (2008).

29. Li, Q. Photoactive Functional Soft Materials: Preparation, Properties, and Applications (Wiley \& Sons, 2018).

30. Bisoyi, H. K. \& Li, Q. Light-driven liquid crystalline materials: from photoinduced phase transitions and property modulations to applications. Chem. Rev. 116, 15089-15166 (2016).

31. Sud, D., Norsten Tyler, B. \& Branda Neil, R. Photoswitching of stereoselectivity in catalysis using a copper dithienylethene complex. Angew. Chem. Int. Ed. 117, 2055-2057 (2005)

32. Yokoyama, Y. Chiral photochromism based on $6 \pi$-electrocyclization. New J. Chem. 33, 1314-1319 (2009).

33. Nakagawa, T., Ubukata, T. \& Yokoyama, Y. Chirality and stereoselectivity in photochromic reactions. J. Photoch. Photobio. C: Photoch. Rev. 34, 152-191 (2018).

34. Feringa, B. L., van Delden, R. A., Koumura, N. \& Geertsema, E. M. Chiroptical molecular switches. Chem. Rev. 100, 1789-1816 (2000).

35. Petermayer, C. \& Dube, H. Circular dichroism photoswitching with a twist: axially chiral hemiindigo. J. Am. Chem. Soc. 140, 13558-13561 (2018).

36. Jurissek, C., Berger, F., Eisenreich, F., Kathan, M. \& Hecht, S. External reversal of chirality transfer in photoswitches. Angew. Chem., Int. Ed. 58, 1945-1949 (2019).

37. Butterfield, A. M., Gilomen, B. \& Siegel, J. S. Kilogram-scale production of corannulene. Org. Process Res. Dev. 16, 664-676 (2012).

38. Borchard, A., Hardcastle, K., Gantzel, P. \& Siegel, J. S. 1,6,7, 10 -Tetramethylfluoranthene: synthesis and structure of a twisted polynuclear aromatic hydrocarbon. Tetrahedron Lett. 34, 273-276 (1993).

39. Borchardt, A., Fuchicello, A., Kilway, K. V., Baldridge, K. K. \& Siegel, J. S. Synthesis and dynamics of the corannulene nucleus. J. Am. Chem. Soc. 114, 1921-1923 (1992). 
40. Duda, B. \& Lentz, D. Simultaneous introduction of trifluoromethyl and $\lambda^{6}$-pentafluorosulfanyl substituents using $\mathrm{F}_{5} \mathrm{~S}-\mathrm{C} \equiv \mathrm{C}_{-} \mathrm{CF}_{3}$ as a dienophile. Org. Biomol. Chem. 13, 5625-5628 (2015).

41. Jones, D. W. \& McDonald, W. S. Exceptional dimerisation of 7,9dimethylcyclopent $[a]$ acenaphthylen-8-one; X-ray crystal structure of the dioldiacetate of one of the dimeric products. J. Chem. Soc. Chem. Commun. 10, 417-418 (1980).

42. Allen, F. H. et al. Tables of bond lengths determined by X-ray and neutron diffraction. Part 1. Bond lengths in organic compounds. J. Chem. Soc. Perkin Trans. 2, S1-S19 (1987).

43. Johnson, E. R. et al. Revealing noncovalent interactions. J. Am. Chem. Soc. 132, 6498-6506 (2010).

44. Houk, K. N. \& Northington, D. J. Photochemistry of cyclopentadienone dimers. Tetrahedron Lett. 13, 303-306 (1972).

45. Fuchs, B. Thermal and photochemical transformation modes of cyclopentadienone-dimers: structural and stereochemical aspects. Isr. J. Chem. 20, 203-207 (1980).

46. B., W. R. \& Roald, H. The conservation of orbital symmetry. Angew. Chem. Int. Ed. 8, 781-853 (1969).

47. Yamaguchi, T., Kobayashi, Y. \& Abe, J. Fast negative photochromism of 1,1'binaphthyl-bridged phenoxyl-imidazolyl radical complex. J. Am. Chem. Soc. 138, 906-913 (2016).

48. Hatano, S., Horino, T., Tokita, A., Oshima, T. \& Abe, J. Unusual negative photochromism via a short-lived imidazolyl radical of 1,1'-binaphthyl-bridged imidazole dimer. J. Am. Chem. Soc. 135, 3164-3172 (2013).

49. Szymański, W., Beierle, J. M., Kistemaker, H. A. V., Velema, W. A. \& Feringa, B. L. Reversible photocontrol of biological systems by the incorporation of molecular photoswitches. Chem. Rev. 113, 6114-6178 (2013).

50. Iwaso, K., Takashima, Y. \& Harada, A. Fast response dry-type artificial molecular muscles with [c2] daisy chains. Nat. Chem. 8, 625-632 (2016).

51. Huang, S.-L., Hor, T. S. A. \& Jin, G.-X. Photodriven single-crystal-to-singlecrystal transformation. Coord. Chem. Rev. 346, 112-122 (2017).

52. Moth-Poulsen, K. \& Bjornholm, T. Molecular electronics with single molecules in solid-state devices. Nat. Nanotechnol. 4, 551-556 (2009).

53. Frisenda, R., Janssen, V. A. E. C., Grozema, F. C., van der Zant, H. S. J. \& Renaud, N. Mechanically controlled quantum interference in individual $\pi$ stacked dimers. Nat. Chem. 8, 1099-1104 (2016).

54. Stern, H. L. et al. Vibronically coherent ultrafast triplet-pair formation and subsequent thermally activated dissociation control efficient endothermic singlet fission. Nat. Chem. 9, 1205-1212 (2017).

55. Smith, M. B. \& Michl, J. Singlet fission. Chem. Rev. 110, 6891-6936 (2010)

56. Zhang, J. et al. Remote light-controlled intracellular target recognition by photochromic fluorescent glycoprobes. Nat. Commun. 8, 987 (2017).

57. Samanta, D. et al. Reversible chromism of spiropyran in the cavity of a flexible coordination cage. Nat. Commun. 9, 641 (2018).

58. Li, R.-J., Holstein, J. J., Hiller, W. G., Andréasson, J. \& Clever, G. H. Mechanistic interplay between light switching and guest binding in photochromic $\left[\mathrm{Pd}_{2}\right.$ dithienylethene $\left.{ }_{4}\right]$ coordination cages. J. Am. Chem. Soc. 141, 2097-2103 (2019)

\section{Acknowledgements}

We thank Prof. Jay S. Siegel, Prof. Cheng Wang, Prof. Ting Lei, Prof. Wei Zhang, Prof. Yun-Bao Jiang, Prof. Yan-Dong Zhang, Prof. Xiang Ma, Prof. Fan Jiang, Xue-Fu Hu, and
Dr. Anirban Pradhan for helpful discussions. We also thank Xiao Tang, You-Zhen Zhuo, Zhi-Hao Li, Yi-Nyu Zhou, Peng Wu, Yu Chen, and Chang-Xia Shi for assistance in experiments. This work was supported by the National Basic Research Program of China (973 Program) (No. 2015CB856505), the National Natural Science Foundation of China (NSFC) (Nos. 21722304, 91427304, 21573181, and 91227111), the Top-Notch Young Talents Program of China and the Fundamental Research Funds for the Central Universities of China (No. 20720160050).

\section{Author contributions}

R.-Q.L. and X.-Y.Y. contributed equally to this work. X.-Y.C., X.-Y.W., R.-Q.L., and X.-Y. Y. conceived and initiated this work. R.-Q.L. and X.-Y.Y. designed and carried out mos experiments (synthesis, characterizations, theoretical calculations, etc.). Y.L. and L.Z. contributed to the mechanism calculations. L.-L.Y. and R.C. contributed to the synthetic work. H.Q., X.-C. W., M.L., and H.X. performed single-crystal X-ray analysis. Y.W., X.-Y. W., J.P., and W.W. provided advices during the experiments. X.-Y.C., X.-Y.W., R.-Q.L., X.-Y.Y., and Y.L. co-wrote the paper. All authors discussed the results and commented on the manuscript.

\section{Competing interests}

The authors declare no competing interests.

\section{Additional information}

Supplementary information is available for this paper at https://doi.org/10.1038/s41467019-13428-3.

Correspondence and requests for materials should be addressed to X.-Y.W., Y.L. or X.-Y.C.

Peer review information Nature Communications thanks Quan Li, Simon Teat and the other, anonymous, reviewer(s) for their contribution to the peer review of this work.

Reprints and permission information is available at http://www.nature.com/reprints

Publisher's note Springer Nature remains neutral with regard to jurisdictional claims in published maps and institutional affiliations.

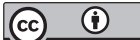

Open Access This article is licensed under a Creative Commons Attribution 4.0 International License, which permits use, sharing, adaptation, distribution and reproduction in any medium or format, as long as you give appropriate credit to the original author(s) and the source, provide a link to the Creative Commons license, and indicate if changes were made. The images or other third party material in this article are included in the article's Creative Commons license, unless indicated otherwise in a credit line to the material. If material is not included in the article's Creative Commons license and your intended use is not permitted by statutory regulation or exceeds the permitted use, you will need to obtain permission directly from the copyright holder. To view a copy of this license, visit http://creativecommons.org/ licenses/by/4.0/.

(C) The Author(s) 2019 